\title{
Management styles and their effects on job satisfaction for radiographers in Gauteng province, South Africa
}

Thandokuhle Emmanuel Khoza ( $\square$ thandokuhlek@dut.ac.za )

Durban University of Technology https://orcid.org/0000-0003-0683-683X

\section{Busisiwe Pauline Nkosi}

Durbna University of Technology

Maureen Nokuthula Sibiya

Durban University of Technology

Research article

Keywords: Radiographers, intent to leave, job satisfaction and management

Posted Date: March 15th, 2020

DOI: https://doi.org/10.21203/rs.3.rs-17235/v1

License: (c) (1) This work is licensed under a Creative Commons Attribution 4.0 International License.

Read Full License 


\section{Abstract}

Background: Management styles have been linked to high turn-over amongst health care professionals. Much of the available literature has been on nursing and other medical professional, while on few studies have been on radiographers. This study explored the influence of management styles on intention to leave amongst radiographers employed by tertiary hospitals in the Gauteng province, South Africa.

Methods: A survey was conducted in four public tertiary hospitals within the Gauteng province. Data was collected from November 2018 to May 2019 and all radiographers who were present at the time of data collection were requested to participate.

Results: The results of the Pearson's test showed that there was a negative correlation between intention to leave and supervision, $r=-.344, p=.000$. In addition, the results also showed that there was difference in satisfaction with supervision across age, gender, race and tertiary hospital.

Conclusion: The findings of this study indicate that management styles in tertiary hospitals affect job satisfaction and ultimately intent to leave. Therefore, it is worth evaluating the type of management styles used by $\mathrm{x}$-ray managers to improve retention of radiographers in public tertiary hospitals. Keywords: Radiographers, intent to leave, job satisfaction and management.

\section{Background}

Leadership is defined as a behaviour of an individual when directing the activities of a group towards a shared goal for a particular organization. Therefore, leaders have an impact on the image of an organization in relation to the type of personnel it attracts and retains. Previous studies have linked leadership style to health care professional turnover $[1,2,3]$. Hence various studies have been done within the health care sector to identify the role leadership in staff retention and job satisfaction $[4,3,5,6,7]$. Similarities have been reported with the type of leadership challenges exerted by managers and these are poor communication, inter-individual conflicts and inter-group conflicts; and transparency $[3,8]$. However, positive leadership style has been reported amongst nurses where they expressed trust and satisfaction with the amount of supervision [8]. These differences are mostly dependant on the type of leadership used by the manager.

The South African health care system consists of the private and the public sector as the major health care providers. It is worth noting that the private sector employs more health care professionals, contrary to the needs of the citizens, where majority rely on the public sector for their medical needs [9]. Management or leadership styles has also been attributed to this maldistribution amongst other factors. This was evident in study amongst medical specialist who opted to permanently vacate their post in the public sector because of managers who failed to support them nor recognize them for the effort they put in their work. Similarly, nurses felt that they were not supported by their managers and were blamed for any wrong doing [5]. In contrast to findings by Sojane [6], where nurses felt that they were supported by their managers and that their supervisors were good leaders. 
Majority of studies conducted to determine the role of leadership in health care profession have been for nursing professionals or medical doctors. Even though these health care professionals work in a hospital setting similar to radiographers, direct inference of leadership style cannot be assumed from them to radiographers. Hence the need to conduct a study amongst radiographers employed by the public sector tertiary hospitals. This study was conducted in public tertiary hospitals within the Gauteng province, reason being they have all the different disciplines within radiography.

\section{Methods}

\section{Design}

A quantitative cross sectional survey was used to guide the study.

\section{Sampling}

At the time of data collection a total of 292 were employed by the four public tertiary hospitals in Gauteng province. A majority of the potential respondents were diagnostic radiographers' respondents at 185; 54 radiation therapists; 31 nuclear medicine; 17 mammography radiographers and the least of the respondents were ultra-sonographers with 5 potential respondents. Hence the researcher's choice to use disproportional stratified sampling. This sampling method would be able to cater for the difference in presentation of the different disciplines in the sampled population.

\section{Data collection}

A self-administered questionnaire was used a method of data collection. Potential respondents were given the questionnaire at the beginning of their working day and was collected by the researcher at end of each working day. In addition, a box was left in central location where completed questionnaires could dropped off at any given time of the day and it was also collected by the researcher at the end of the working week. The questionnaire was distributed to four public tertiary hospitals within the Gauteng province in South Africa. The target population for this study was the different disciplines within radiography, namely diagnostic radiographers; radiation therapists; nuclear medicine radiographers; mammography radiographers and ultra-sonographers. Data collection process began in November 2018 and was completed in June 2019.

\section{Results}

\section{Respondents' characteristics}


The questionnaire was completed by 181 respondents, of which $60 \%$ were females and $40 \%$ were males. The majority of the participants were Millennials $80 \%$, Generation X accounted for $31 \%$ of the population and only $19 \%$ were Baby Boomers. There was also a difference noted in the presentation of race where, $68 \%$ of respondents were Black, $17 \%$ were White, $7.7 \%$ Indians, Coloured $5.5 \%$ and other $1 \%$. The majority of the respondents, were employed for a period of 1-10 years, while those who were employed for a period greater than $10-20$ years made up $28 \%$ of the respondents and only $20 \%$ were employed for a period greater than 20 years. Diagnostic radiographers had the majority of the respondents at $55 \%$, radiation therapists $24 \%$, nuclear medicine $13 \%$, mammography radiographers $5 \%$ and ultra-sonographers had only $3 \%$ of the respondents. In the four tertiary hospitals that were included in the study, $42 \%$ of the respondents were from tertiary hospital1, 30\% from tertiary hospital 2,12\% tertiary hospital 3 and $17 \%$ were employed at tertiary hospital 4.

\section{Satisfaction with supervision}

During data analysis, confirmatory factor analysis was performed to ensure that the statements related and linked to management. Internal consistency was checked on the 8 statements related to satisfaction with supervision, a Cronbach's alpha measure calculated was A one sample t-test was performed on to determine if supervisors provided favourable working conditions. The results showed that there was a significant disagreement $(M=3.3048)$ that supervisors were able to create favourable working conditions, $t(181)=5.219, p<.0005$. Furthermore, a Pearson's correlation test was performed to determine if there was a correlation with intention to leave (ITL) and satisfaction with supervision. The results showed that there was a negative correlation between intention to leave and supervision, $r=-.344, p=.000$ and this indicates that respondents who are satisfied with their supervisors have no intention to leave. Similarly the results of regression analyses showed that independent variables account for $16.4 \%$ (R2 = .164) of the variability in the dependent variable, intention to leave, $F(9,169)=3.695, p<.0005$. Supervision is a significant predictor of ITL, $\beta=-.270, p=.028$. Stepwise regression was used to test intention to leave and account for $14.5 \%\left(R^{2}=.145\right)$ of the variability in intention to leave, $F(2,176)=14.867, p<.0005$. Satisfaction with supervision $(\beta=-.355, p=.001)$ is significant predictors of intention to leave.

There was an additional significance difference across gender, $t(179)=-2.277, p=.024$, males (M3.1448) were satisfied with supervision than females. The results of the Welsh test $(4,6.873)=4.363, p=.045$ indicated that Whites were more satisfied with supervision than Black Africans. Similarly, the results of the Spearman's correlation demonstrated a difference across age. There was a positive correlation between age and satisfaction with supervision, rho=180, $p=.166$, older respondents were more satisfied with supervision. There was also a negative correlation between age and intention to leave, rho $=-.031$, $p=-166$. Older participants had no intention to leave.

The results of the ANOVA test showed that there was significant difference with supervisor satisfaction across tertiary hospitals $F(3,178)=18.104, p=.000$. Respondents from tertiary hospital 2 , were more 
satisfied with their supervisors than those employed at tertiary hospital 2 and 3 and 4 . Whereas respondents employed in tertiary hospital 1 were more satisfied with their supervisors more than those employed in hospital 3 and 4 . The questionnaire provided the respondents with a blank space where they could provide any additional information related to their satisfaction with supervision. A variety of responses were obtained and these included poor communication styles; favouritism; unprofessional; non-consultative; no recognition; unqualified managers and unsupportive managers.

\section{Discussion}

Our study had a reasonable response rate, $62 \%$ of the questionnaire were completed and returned to the researcher. According to Fincham [10], a response rate of $60 \%$ is acceptable for a survey. The results in this study showed that satisfaction with supervision was significantly associated with intention amongst radiographers employed by public tertiary hospitals in Gauteng province. This was demonstrated by the results of the stepwise regression amongst other analytical tests where satisfaction with supervision $(\beta=$ $-.355, p=.001)$ is significant predictors of intention to leave. Similarly to studies conducted amongst health care professionals in South Africa that have previously reported that the public sector health care professionals have a higher intent of vacating their post and poor management being amongst the leading factors [11]. In contrast to findings by Sojane [6], where majority of the nurses believed that their managers were good leaders, good managers and were also supportive.

Our findings further showed that there was a difference in the satisfaction with supervision style across the four tertiary hospitals that were included in our study. Radiographers employed in tertiary hospital number two showed the most significant satisfaction with the type of supervision they received from their manager. Whereas radiographers employed in tertiary hospital number two, showed significant satisfaction with their supervisors over hospital three and four. This was also supported by the respondent's responses in the open space to provide additional comments, where majority of the negative comments were from tertiary hospital 3 and 4 . There was no direct correlation from the results in the study to account for this difference. Similarly, there was direct result to account for the difference with satisfaction by supervision across gender. These differences would require additional studies to explore their causes.

Furthermore, there was a difference that was noted across the different age groups. This could be attributed to the difference in personalities and work ethics associated with the different age groups. Millennials are associated with high expectations from their managers to assist them in achieving their professional goals, whereas Generation X place great significance balance about work and like and care less about advancements $[8,12]$. The older respondents were more satisfied with the level of supervision they received from their managers and their age category placed them under Baby Boomers and Generation X. For this reason the older respondents had no intention to leave. Previous studies have reported that Baby Boomers tend to have higher levels of satisfaction with their supervisor-subordinate 
relationship, teamwork, affective commitment and lower intentions to vacate their post in comparison to Generation $X$ and $Y[11,13]$. To account for these differences in satisfaction with supervision across gender, tertiary hospital, race and age further studies are needed to be conducted amongst radiographers.

\section{Limitations}

The study was only conducted in public tertiary hospitals, therefore the results cannot be generalized to other settings such as the private sector. Reason being, the reporting channels might not be the same. Also, the study did not test any of the know leadership traits such as transformational, collaborative, shared, autocratic and ethical leadership. Testing these leadership styles would have helped to identify the most preferred leadership style by radiographers and which leadership style is associated with a high attrition rate.

\section{Recommendations}

The requirements to be appointed as a radiography manager should be amended to require a mandatory management qualification and this could improve some of the concerns raised by the respondents. Once appointed, managers should attend management workshops and seminars to continuously improve their management skills. Also, additional studies need to be conducted amongst radiographers in order to identify the most suitable leadership style.

\section{Relevance}

There is a mal-distribution of health care professionals between the public and the private sector in South Africa. The private sector being known to have a higher ration of health care professionals in comparison to the public sector. The factors which result in this mal-distribution within radiography have been assumed from other health care professionals, hence the need for the study. The results of the study identified management styles as a significant contributor on intent to leave amongst radiographers.

\section{Conclusion}

The results of this study have shown that there is direct relationship between management style used by radiography managers and intention to leave amongst radiographers employed by public tertiary hospitals in the Gauteng province. Radiographers who were more satisfied with management style used by their managers were less likely to have intentions of voluntarily vacating their posts. Therefore, it is imperative for managers to explore the type of management style most suitable for their department and preferred by their sub-ordinates. In addition, the government could enhance capacity of radiography managers by providing continuous support for all those in management. Alternatively a mandatory requirement should be that mangers must have a post graduate qualification in radiography or management qualification in order to occupy any post in management. 


\section{Abbreviations}

ITL

intention to leave.

\section{Declarations}

\section{Acknowledgements}

The author is grateful to the Gauteng Department of Health for granting permission to conduct the study in the public tertiary hospitals within the province.

\section{Authors' contribution}

TK: researcher, concept and study design, BN: Co-supervisor critical revision and editing and NS: Supervisor critical revision and editing. All authors have read and approved the manuscript.

\section{Funding}

This study was funded by the National Research Foundation (NRF) and the Durban University of Technology.

\section{Availability of data and materials}

Copies of datasets used for this study may be available from the corresponding author on reasonable request.

\section{Ethics approval and consent to participate}


The study was carried out in partial fulfilment of a $\mathrm{PhD}$ in Health Sciences with the Durban University of Technology and was approved by the Durban University of Technology Institutional Research Ethics Committee (IREC 115/18). No consent form was obtained from participants to complete the questionnaire, however, a cover letter detailing the aims and objectives of the study was attached.

\section{Consent for publication}

Not applicable.

\section{Competing interests}

The authors declare that they have no competing interests.

\section{Author details}

${ }^{1}$ Department of Radiography, Durban University of Technology, Durban, South Africa. ${ }^{2}$ Department of Radiography, Durban University of Technology, Durban, South Africa. ${ }^{3}$ Faculty of Health Sciences, Durban University of Technology, Durban, South Africa.

\section{References}

1. Bonenberger M, Aikins M, Akweongo P, Wyss K. The effects of health worker motivation and job satisfaction on turnover intention in Ghana: a cross-sectional study. Human Resources for Health. 2014;12(43):1-12.

2.

Kim JH, Kim CS, Kim JM. Analysis of the effect of leadership and organizational culture on the organizational effectiveness of radiological technologist's working environment. Radiography. 2011;17:201-6.

3.

Al-Sawai A. Leadership of Healthcare professionals: Where do we stand? Oman Medical Journal. 2013;28(4):285-7.

4.

Watson LM. Leadership's influence on job satisfaction. Radiol Technol. 2009;80(4):297-306. 5 .

Munyewende PO, Rispel LC, Chirwa T. Positive practice environment influences job satisfaction of primary health care clinical nursing managers in two South African provinces. Human Resources for Health. 2014;27(12):1-14.

6. 
Sojane JS, Klopper HC, Coetzee SK. Leadership, job satisfaction and intention to leave among registered nurses in the North West and Free State province of South Africa. Curationis. 2016;39(1):1-10.

7.

Asiri SA, Wesley WR, Al-Surimi K, Da'ar OO, Ahmed A. The association of leadership styles and empowerment with nurses' organizational commitment in an acute health care setting: a cross sectional study. 2016; 15:38.

8.

Wagner JD, Bezuidenhout MC, Roos JH. Communications satisfaction of professional nurses working in public hospitals. J Nurs Manag. 2015;23:974-82.

9.

Coetzee SK, Klopper HC, Ellis SM, Aiken LH. A tale of two systems - nurse practice environment, wellbeing, perceived quality of care and patient safety in private and public hospitals in South Africa: a questionnaire survey. Int J Nurs Stud. 2013;50:162-73.

10.

Fincham JE. Response rates and responsiveness for survey, standards and the journal. American Journal of Pharmaceutical Education. 2008;72(2):1-3.

11.

Ashmore J. Going private: a qualitative comparison of medical specialists' job satisfaction in the public and private sectors of South Africa. Human Resources for Health. 2013;11:1-12.

12.

United Nations Joint Staff Pension Fund. Traditionalist B, Boomers, Generation X, Generation Y. (and Generation Z) working together: how different are they? Fiction and fact. 2008. New York: United Nations. 13.

Brunetto Y, Shriberg A, Farr-Wharton R, Shacklock K. The importance of supervisor-nurse relationships, teamwork, wellbeing, affective commitment and retention of North American nurses. J Nurs Manag. 2013;21(6):827. 